\title{
First Report on Transplacental Transmission of Anaplasma marginale in Neonatal Dairy Calves from District Jhang, Punjab, Pakistan
}

\author{
Farhan Ahmad Atif ${ }^{1}$ *, Kashif Hussain ${ }^{1,2}$, Muhammad Fiaz Qamar ${ }^{3}$, Muhammad Sohail Sajid ${ }^{2}$, Muhammad Arfan \\ Zaman $^{3}$ and Muhammad Kamran Rafique ${ }^{3}$ \\ ${ }^{1}$ Medicine Section, Department of Clinical Sciences, College of Veterinary and Animal Sciences, Jhang; (Sub-campus) \\ University of Veterinary and Animal Science, Lahore, Pakistan \\ ${ }^{2}$ Department of Parasitology, Faculty of Veterinary Science, University of Agriculture, Faisalabad, Pakistan \\ ${ }^{3}$ Department of Pathobiology, College of Veterinary and Animal Sciences, Jhang; University of Veterinary and Animal \\ Science, Lahore, Pakistan \\ *For correspondence: farhan.atif@uvas.edu.pk; atifvet_2000@yahoo.com \\ Received 22 June 2020; Accepted 18 November 2020; Published 25 January 2021
}

\begin{abstract}
The current study was planned to evaluate the transplacental transmission potentials of Anaplasma marginale among naturally infected adult dairy cattle in district Jhang, Punjab, Pakistan. A dairy farm was selected after a district level survey having highest number of blood smear, cELISA and PCR positives of A. marginale infected pregnant crossbred cows (Holstein Friesian $\times$ Cholistani). Blood samples were collected from dams (within 4 months of their pregnancies and at the time of parturitions) as well as from the new-born calves (before colostrum feeding within $3 \mathrm{~h}$ of the birth). Eighty pregnant cows were screened through the cELISA and PCR. Out of these, 54 were found positive for anaplasmosis. Further follow up revealed that 38 cows remained positive at the time of parturition. Finally, based on the criteria, 32 calves without colostrum feeding qualified for the vertical transmission trial. The results of present study revealed that 28 (9/32) and 13\% (4/32) of the neonatal calves acquired intrauterine infection confirmed by cELISA and PCR, respectively. Overall occurrence of the transplacental transmission was $31 \%$. Nevertheless, we concluded that transplacental transmission occurs and this route of transmission, can lead to a significant number of neonatal deaths. Hence, the transplacental route of disease transmission should also be considered for devising the prevention and control strategies regarding anaplasmosis in the dairy cattle. (C) 2021 Friends Science Publishers
\end{abstract}

Keywords: Anaplasma; Transplacental transmission; cELISA; PCR; Punjab; Pakistan

\section{Introduction}

Anaplasmosis is a tick-borne infectious disease, caused by an obligatory intracellular pathogen of genus Anaplasma (A.); causing heavy economic losses, worldwide including Pakistan (Sajid et al. 2014; Atif 2016; Abbas et al. 2020; Spare et al. 2020). The bovine anaplasmosis (BA), mostly prevalent in the tropical, and the subtropical regions, is transmitted biologically by the ticks, mechanically by the mosquitoes, lice, biting flies, contaminated fomites and trans placentally through placenta from mother to the offspring (Aubry and Geale 2011; Costa et al. 2016; Karim et al. 2017; Rehman et al. 2019). Rhipicephalus microplus is the major vector of the BA, worldwide; nevertheless, competent vector of the BA in the region is not known. Transplacental transmission of anaplasmosis occurs mainly during the second and third trimesters of pregnancy (Zaugg and Kuttler 1984; Ribeiro et al. 1995; Grau et al. 2013) and may lead to death of the new-borne calves (Vos et al. 1976; Pypers et al. 2011; Santarosa et al. 2013). Transplacental transmission potential permits the bacterium to adapt different transmission strategies (Estrada-Peña et al. 2009). Usually, transplacental transmission has been commonly described during the case series, experimental and longitudinal studies (Pypers et al. 2011; Grau et al. 2013; Silva et al. 2015; Costa et al. 2016; Nazar et al. 2018; Henker et al. 2020). Anaplasma is being transferred from the dams to the calves through placenta (Grau et al. 2013; Silvestre et al. 2016; Costa et al. 2016). Different studies reported the mortality in calves of the infected dams due to vertical transmission of the pathogen (Pypers et al. 2011; Santarosa et al. 2013; Henker et al. 2020).

Molecular and serological techniques are more specific and sensitive towards the detection of anaplasmosis as compared to the conventional blood smear microscopy (Brito et al. 2007; Atif, 2016; Wen et al. 2016; Farooqi et al.

To cite this paper: Atif FA, K Hussain, MF Qamar, MS Sajid, MA Zaman, MK Rafiq (2021). First report on transplacental transmission of Anaplasma marginale in the neonatal dairy calves from district Jhang, Punjab, Pakistan. Intl J Agric Biol 25:541-546 
2018; Rehman et al. 2019). The improved competitive ELISA (cELISA) is the most used serological test for the detection of Anaplasma antibodies in cattle with higher sensitivity (100\%) and specificity (99.7\%) (Chung et al. 2014). This uses a monoclonal antibody (MAb) specific for the surface protein 5 (MSP5). Confirmatory diagnosis is usually based on the serology followed by the molecular tests (Atif 2016). Only one study has reported the transplacental transmission in Khyber Pakhtunkhwa province, Pakistan (Nazar et al. 2018). However, status of the trans-placental transmission in the natural infection of anaplasmosis in the dairy cattle is lacking from Punjab, Pakistan. Therefore, the current study was planned to evaluate the trans-placental transmission potentials of $A$. marginale in the adult dairy cattle from Jhang district, Punjab, Pakistan.

\section{Materials and Methods}

\section{Study location and sampling criteria}

Adairy farm located at Moza KotSai Singh, Jhang was selected $\left(31.2761^{\circ} \mathrm{N}, 72.3496^{\circ} \mathrm{E}\right)$, based on highest number of positive pregnant crossbred (Holstein Friesian $\mathrm{x}$ Cholistani) dairy cattle, identified from a district level survey. In Jhang district, molecular based herd prevalence of A. marginale in crossbred and exotic cattle was 35.48 and 56.76\%; respectively (Annual Project Report, Pakistan Science Foundation, Pakistan, Project \# PSF/NSLP-UVAS (967). First batch of the blood samples were collected from asymptomatic carrier cows (within 120 days of the gestation/before parturition). The second batch of the samples was collected just after parturition and subsequently, from their newborn calves (before colostrum feeding). However, there was a history of clinical disease seven months prior to sampling. Species of ticks were identified based on the morphological features using taxonomic key (Walker et al. 2014). The blood samples collected from the dairy farm were transported to laboratory in an ice box for further analysis.

\section{Serology}

The blood samples were collected in a Vacutainer (BD Vacutainer ${ }^{\circledR} \mathrm{SST}^{\mathrm{TM}}$ ), containing polymer gel and spraycoated silica for separation of the sera. The samples were centrifuged for $5 \mathrm{mins}$ at $5000 \mathrm{rpm}$. Sera were separated and stored at $-20^{\circ} \mathrm{C}$ until used for cELISA.

\section{Competitive ELISA}

The cELISA was performed using Anaplasma Antibody Test Kit (cELISA v. 2; Catalog No. 283-2) as described by Veterinary Medical Research \& Development (MRD) Inc., Pullman, WA, USA. The wells with no color change were considered as positive and those with blue color were considered as negative. The intensity of blue described the percentage of positivity. Furthermore, the results were recorded with the help of ELISA reader (Biobase-EL10A; China) at $630 \mathrm{~nm}$ wavelength. The samples with inhibition $\geq 30 \%$ were considered positive. Conversely, the samples with $<30 \%$ inhibition were considered negative.

\section{Isolation of the genomic DNA from the blood samples}

The DNA was extracted using Gene JET Whole Blood Genomic DNA Purification Mini Kit (Thermofisher Scientific; Catalogue No. K0782) following the manufacturer's guidelines. Briefly, $200 \mu \mathrm{L}$ of the blood sample was filled in an Eppendorf tube and 'Proteinase K Solution' $(20 \mu \mathrm{L})$ was added. Later, lysis solution $(400 \mu \mathrm{L})$ was added and mixed by vortexing (MS-X DLAB; U.S.A.) followed by an incubation at $56^{\circ} \mathrm{C}$ in water bath (APin, Samheung Energy) for 10 mins and vortexed. Subsequently, $200 \mu \mathrm{L}$ of ethanol (96-100\%) was added followed by the reverse pipetting. The mixture was shifted to a spin column containing collection tube included in the kit, and centrifuged $(8,000 \mathrm{rpm})$ for $1 \mathrm{~min}$ in microcentrifuge machine (D2012plus DLAB, USA). The column was washed twice with $500 \mu \mathrm{L}$ Wash Buffer and centrifuged. At the end, 200 $\mu \mathrm{L}$ elution buffer was added to remove the genomic DNA. Finally, the spin column was disposed off after centrifugation $(10,000 \mathrm{rpm}$ for $1 \mathrm{~min})$. The micro-centrifuge tube containing the purified DNA was stored at $-20^{\circ} \mathrm{C}$ until used for further processing.

\section{PCR}

The PCR was based on amplification of MSP1b gene using master-mix (Dream taq green PCR master mix; catalogue No. K1081). The MAR1bB2 primers (forward: 5'-GCT CTA GCA GGT TAT GCG TC-3' and reverse primer 5'CTG CTT GGG AGA ATG CAC CT-3') were utilized for the detection of 265 base pair DNA product, which specifically amplify A. marginale in the bovine blood samples (Bilgiç et al. 2013). A total of 35 cycles (initial heating and denaturation at $94^{\circ} \mathrm{C}$ for 3 mins, annealing at $55^{\circ} \mathrm{C}$ for 50 seconds and extension at $72^{\circ} \mathrm{C}$ for $1 \mathrm{~min}$ using thermal cycler (T100; Bio Rad, U.S.A.). Positive control was obtained from the Institute of Pure and Applied Biology, Bahauddin Zakariya University (BZU), Multan, Pakistan; isolated from whole frozen blood of Bubalus bubalis (Layyah district, Pakistan). Whereas sterile distilled water was used as a negative control. Furthermore, the PCR products along with positive and negative controls were analyzed on $1.3 \%$ agarose gel having ethidium bromide at the rate of $0.5 \mu \mathrm{g} / \mu \mathrm{L}$ of gel in $1 \mathrm{X}$ TAE buffer using $100 \mathrm{bp}$ DNA ladder (Gene Ruler 100 bp DNA Ladder, Catalog No. SM0323; Thermo-Fisher Scientific, USA). Gel electrophoresis was performed at $90 \mathrm{~V}$, and $400 \mathrm{amp}$ (maximum) for $30 \mathrm{~min}$ or until the dye migrated to the twothird of the gel. Finally, the gel image was captured using 
Transilluminator (Catalog no. MUVB-112; Major Scientific, USA).

\section{Results}

\section{Transplacental transmission}

From the sampling frame a dairy farm was selected for transplacental transmission study having highest number of positive pregnant crossbred cattle after district level survey. At an initial screening, 54 pregnant animals were found positive for A. marginale (within 120 days of gestation) and 38 cows remained positive until parturition with both detection methods ( $2^{\text {nd }}$ blood sampling). We managed to get blood of 32 newborn calves (before colostrum's feeding) out of 38 positive dams. Blood samples of the six calves were not taken because they had ingested colostrum. In the present study, overall transplacental transmission rate of $A$. marginale in neonatal crossbred calves was $31 \%$; whereas occurrence of $12(4 / 32)$ and $28 \%$ (9/32) was noticed using PCR and cELISA, respectively. The DNA product with 265 bp was detected using PCR. Three calves found positive from both detection methods (Table 1; Fig. 1-3). The cutoff values for validation of negative control with optical density ranging from $>0.40$ to $<2.10$ and inhibition of $>30 \%$ for positive controls was considered. Furthermore, Rhipicephalus microplus and Hyalomma anatolicum species of ticks were identified based on the morphological features from the selected dairy farm.

\section{Discussion}

Most of the earlier reports have demonstrated transplacental transmission for A. marginale and A. phagocytophilum during case series and experimental studies (Pypers et al. 2011; Grau et al. 2013; Silva et al. 2015; Costa et al. 2016; Nazar et al. 2018; Stuen et al. 2018; Henker et al. 2020). However, limited longitudinal studies have mentioned intrauterine transmission during natural infection. So far, there is a single report of the vertical transmission from Khyber Pakhtunkhwa (KPK), Pakistan with occurrence of $13.7 \%$ transplacental transmission rate of $A$. marginale in cattle (Nazar et al. 2018). Additionally, during a survey from limited samples, prevalence of A. marginale was mentioned as 45.83 and $34.3 \%$ using qPCR (MSP1a gene) and indirect ELISA (iELISA), respectively from Peshawar (KPK). Nevertheless, they did not mention the sampling sources, disease status of dams (at parturition), breed of new-born calves and their dams as well as whether neonates have ingested colostrum before blood sampling. These are important aspects prior to validate transplacental transmission. In the present study, for the detection of anaplasmosis MSP1b and recombinant MSP5 (rMSP5) genes were utilized for PCR and cELISA; respectively. Furthermore, the different gene targets for various PCRs and serodiagnostic kits yield variable sensitivity and specificity (cELISA vs. iELISA) (Chung et al. 2014; Atif 2015).
Table 1: Results of competitive ELSIA with percent inhibition and their interpretation for the detection of anaplasmosis in selected cattle population of Jhang district, Punjab, Pakistan

\begin{tabular}{|c|c|c|c|c|}
\hline $\begin{array}{l}\text { Sr. } \\
\text { No. }\end{array}$ & $\begin{array}{l}\text { Sample ID on ELISA } \\
\text { plate }\end{array}$ & $\begin{array}{l}\text { OD } \\
\text { Value }\end{array}$ & $\begin{array}{l}\% \\
\text { Inhibition }\end{array}$ & Interpretation \\
\hline 1 & A1 & 0.64 & 57.33333 & $\begin{array}{l}\text { Positive } \\
\text { Control }\end{array}$ \\
\hline 2 & A2 & 1.5 & 0 & Negative Control \\
\hline 3 & A3 & 1.601 & -6.73333 & Negative \\
\hline 4 & A4 & 1.443 & 3.8 & Negative \\
\hline 5 & A5 & 1.283 & 14.46667 & Negative \\
\hline 6 & A6 & 0.718 & 52.13333 & Positive* \\
\hline 7 & A7 & 1.493 & 0.466667 & Negative \\
\hline 8 & A8 & 0.845 & 43.66667 & Positive* \\
\hline 9 & A9 & 0.708 & 52.8 & Positive* \\
\hline 10 & A10 & 1.72 & -14.6667 & Negative \\
\hline 11 & A11 & 1.68 & -12 & Negative \\
\hline 12 & A12 & 0.68 & 54.66667 & Positive* \\
\hline 13 & B1 & 1.32 & 12 & Negative \\
\hline 14 & B2 & 1.671 & -11.4 & Negative \\
\hline 15 & B3 & 0.83 & 44.66667 & Positive* \\
\hline 16 & B4 & 1.29 & 14 & Negative \\
\hline 17 & B5 & 1.88 & -25.3333 & Negative \\
\hline 18 & B6 & 1.364 & 9.066667 & Negative \\
\hline 19 & B7 & 1.674 & -11.6 & Negative \\
\hline 20 & B8 & 0.902 & 39.86667 & Positive* \\
\hline 21 & B9 & 1.56 & -4 & Negative \\
\hline 22 & B10 & 1.801 & -20.0667 & Negative \\
\hline 23 & B11 & 0.742 & 50.53333 & Positive* \\
\hline 24 & B12 & 1.308 & 12.8 & Negative \\
\hline 25 & $\mathrm{C} 1$ & 1.532 & -2.13333 & Negative \\
\hline 26 & $\mathrm{C} 2$ & 0.684 & 54.4 & Positive* \\
\hline 27 & $\mathrm{C} 3$ & 1.637 & -9.13333 & Negative \\
\hline 28 & $\mathrm{C} 4$ & 1.781 & -18.7333 & Negative \\
\hline 29 & C5 & 1.407 & 6.2 & Negative \\
\hline 30 & C6 & 0.821 & 45.26667 & Positive* \\
\hline 31 & C7 & 1.583 & -5.53333 & Negative \\
\hline 32 & $\mathrm{C} 8$ & 1.734 & -15.6 & Negative \\
\hline 33 & C9 & 1.625 & -8.33333 & Negative \\
\hline 34 & $\mathrm{C} 10$ & 1.742 & -16.1333 & Negative \\
\hline
\end{tabular}

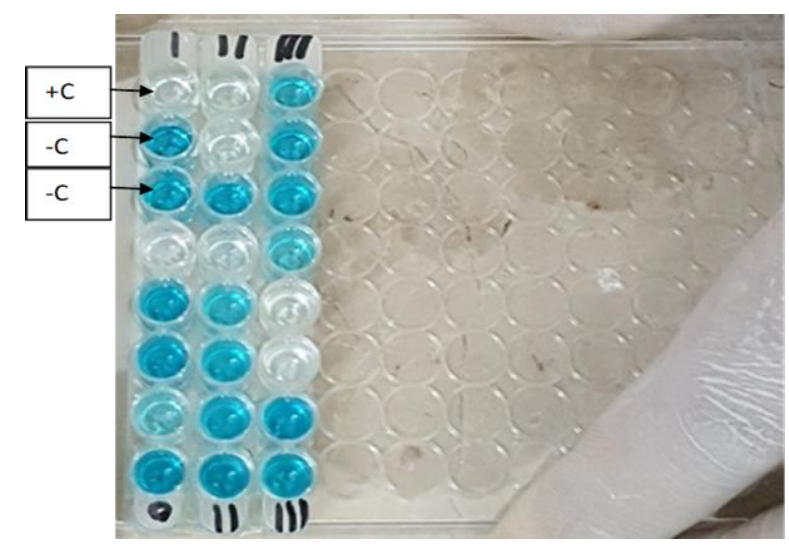

Fig. 1: The cELISA results showing color change after addition of stop solution and arrow heads indicate positive and negative samples. The $-\mathrm{C}$ and $+\mathrm{C}$ on top of the wells represent negative and positive controls; respectively

Ixodidae ticks, act as biological vector and play essential role in spread and propagation of disease during 
different lifecycle stages. Biological transmission $A$. marginale is accomplished through ticks, mechanically through biting flies, fomites and tans-placental spread (during $3^{\text {rd }}$ and $4^{\text {th }}$ trimesters of pregnancy) (Dikmans 1950; Zaugg 1985; Rikihisa 1991). Biting insects chiefly from order Dipteran and Phthiraptera such as horse flies (Tabanus), Stable flies (Stomoxys), deer flies (chrysops), eye flies (Hippelates) and mosquitoes (Psorophora) contribute for mechanical transmission. Contrary to other tick-borne diseases anaplasmosis is also predominant in tick free areas. In tick free zones the flies meaningfully contribute for mechanical transmission of disease (Dikmans 1950; Ewing 1981; Hawkins et al. 1982; Silva et al. 2014). The exotic and crossbred cattle had genetic susceptibility to ticks and tick-bone diseases; remain persistently infected with higher potential for vertical transmission.

The cELISA detects $A$. marginale antibodies in undiluted serum samples by inhibiting the binding of horseradish peroxidase (HRP) labeled monoclonal antibody (conjugate) coated with each wells of microtiter plate. Recombinant major surface protein5 (rMSP5) along with Glutathione S-transferase fusion protein is attached with the plate wells as antigen. Glutathione S-transferase fusion protein help to minimize cross reaction with bacterial proteins. This test proved $99.7 \%$ specific and $100 \%$ specific (Chung et al. 2014). The discrepancy in our molecular and serological results may be due to the fact that dams were carrier during gestation. We detected higher persistently infected cows, transferred immunoglobulins to their calves as detected by cELISA. The calves that were positive through both of the detection methods (cELISA and PCR) were justified as they had the latent infection. Nevertheless, neonates who were positive with PCR and negative through cELISA were suggestive of the recent infection. However, young ones with positive cELISA and negative PCR possibly have had very low bacteremia and infection could have been controlled by the fetus (Zaugg and Kuttler 1984). Immunosuppressive conditions during the gestation period also contribute in the reoccurrence of infection in dams and increase the chances of transplacental transmission of infections. During peripartum period, transitional immunosuppression occurs which leads to the subclinical infection and may be the possible cause of an in-utero transmission of anaplasmosis (Silva and Fonseca 2014). Furthermore, Pypers et al. (2011) reported that there is a correlation between immunosuppression of dams and death in calves. Earlier reports published on the congenital anaplasmosis in calves had led to undiagnosed neonatal deaths (Grau et al. 2013).

Different diagnostic tests with variable detection limits can yield different vertical transmission rates. For example, Grau and associates has detected higher sero-positivity using indirect fluorescent antibody test $(100 \%)$ as compared to the indirect ELISA (97\%) during a survey. The PCRbased occurrence of the transplacental transmission was $10.5 \%$ in Braford calves from Pelotas, Brazil (Grau et al.

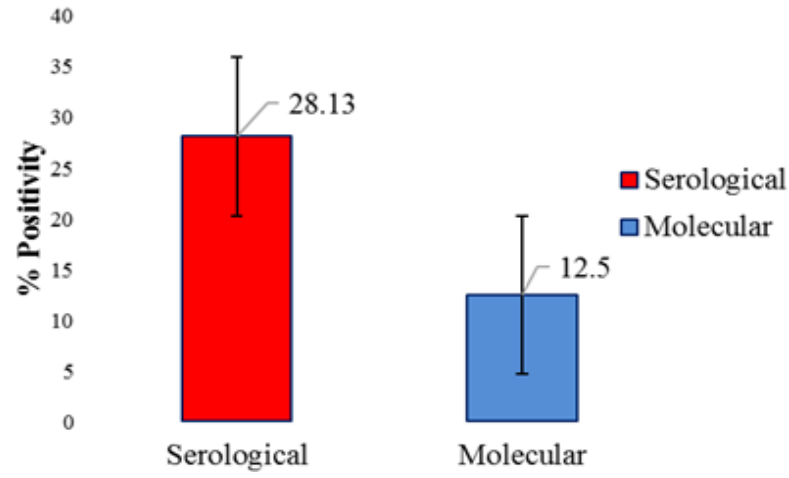

Fig. 2: Transplacental transmission of A. marginale detected by serological (cELISA) and molecular (PCR) techniques. The error bar indicates standard error

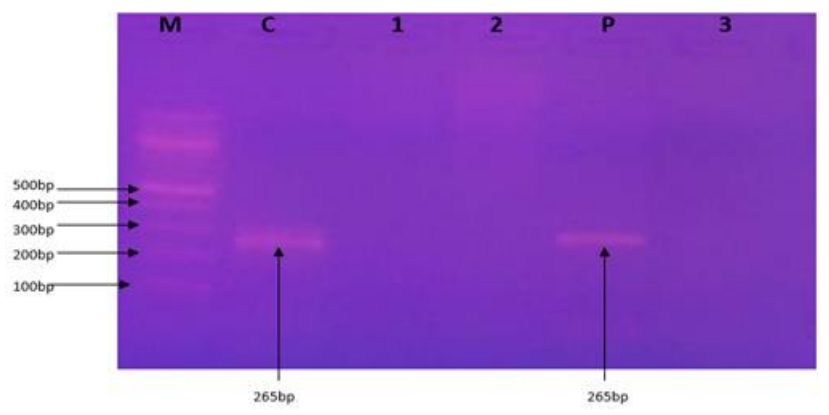

Fig. 3: Agarose gel electrophoresis of A. marginale targeting cytob1 gene with DNA product of 265 bp visualized on Transilluminator $(\mathrm{M}=$ Marker/Ladder; $\mathrm{C}=$ Control; $\mathrm{P}=$ Positive sample)

2013). Furthermore, they mentioned that not a single calf was found positive for anaplasmosis with ELISA and $10 \%$ of the calves were positive with IFAT. In contrast, we noticed the transmission rate of $28 \%$ with cELISA, perhaps due to larger number of the carrier animals in our study. Nevertheless, Silvestre et al. (2016) demonstrated occurrence of $10 \%$ vertical transmission in male Holstein calves from Minas Gerais, Brazil. They depicted lower transmission rate of $A$. marginale using nested PCR (MSP4) than our results, possibly due to difference in regional tick control and managemental practices. Likewise, transplacental transmission rate of $15.6 \%$ was reported by Potgieter and Rensburg (1987) in Anaplasma-infected calves kept under laboratory conditions in South Africa using a serological test, rapid card agglutination test. Conversely, Costa et al. (2016) mentioned higher $26.47 \%$ transplacental positivity in the crossbred neonatal calves using the nested PCR. Siva and his colleagues from Rio de Janeiro reported higher occurrence of the transplacental transmission $41 \%$ (Silva et al. 2015). Likewise, Salabarria and Pino (1988) from Cuba mentioned higher $86.4 \%$ (32/37) frequency of vertical transmission under clinical anaplasmosis in the last month of the gestation. The variation in results might be due to different of diagnostic 
techniques, genetic diversity and different agro-climatic conditions of area (Costa et al. 2016). Taken together, lower transmission rate might be due to susceptibility of dams towards infection and environmental conditions in comparison to Jhang, Pakistan.

Our findings are supported by Pohl and their colleagues; they mentioned that the vertical transmission in cattle is mainly due to persistent infection in a population (Pohl et al. 2013). The rate of in-utero transmission depends upon the timing of fetal infection during gestation as the occurrence of transmission is higher at the end of gestation. Nonetheless, Henker and co-workers identified anaplasmosis/babesiosis infected cases of abortion; stillbirth and neonatal deaths in neonatal Angus/crossbred beef calves from Rio Grande do Sul (Southern Brazil). They stressed the importance of considering anaplasmosis in differential diagnosis (Henker et al. 2020). Concisely, the transmission potential may vary due to the detection methods (as well as their sensitivities), climatic conditions, region, host/breed, vectors, and pathogenic characteristics (Costa et al. 2016).

\section{Conclusion}

Anaplasmosis might be one of the major causes of mortality in young cattle calves in Pakistan. We reported first occurrence of the transplacental transmission of $A$. marginale in the pregnant dairy cows in Jhang district of Punjab, Pakistan using cELISA and PCR. This would be an important route of Anaplasma transmission in cattle and can lead to significant number of neonatal deaths. Based on our conclusion, following recommendations are suggested: (a) Anaplasmosis might be one of the major causes of mortality in young cattle calves, further studies are needed to explore the transplacental transmission potential of the disease in buffalo calves and other domestic animals. (b) Early treatment of the calves or preventive therapy can minimize the risk of mortality. (c) Enhancing dam's immunity in general or specifically against bovine anaplasmosis can help to reduce calf mortality.

\section{Acknowledgement}

The research was financially supported by Pakistan Science Foundation, Islamabad, Pakistan having Project No. PSF/NSLP/P-UVAS (697). We are thankful to farmer of Masha Allah Dairy Farm for execution of research and laboratory staff for sampling and research work.

\section{Author Contributions}

FAA was involved in the conceptualization, planning, interpretation of results, and proof-reading; $\mathrm{KH}$ typed the manuscript, performed research work, and made illustrations; MSS planned the study design and proof-read; MFQ, MAZ and MKR helped in the conceptualization, and interpretation of the results.

\section{References}

Abbas MZ, M Saqib, F Deeba, MS Sajid (2020). Impact of sub-clinical anaplasmosis on haemato-biochemical parameters of naturally infected camels (Camelus dromedaries). Pak J Agric Sci 57:963-967

Atif FA (2016). Alpha proteobacteria of genus Anaplasma (Rickettsiales: Anaplasmataceae): Epidemiology and characteristics of Anaplasma species related to veterinary and public health importance. Parasitol 143:659-685

Atif FA (2015). Anaplasma marginale and Anaplasma phagocytophilum: Rickettsiales pathogens of veterinary and public health significance. Parasitol Res 114:3941-3957

Aubry P, DW Geale (2011). A review of bovine anaplasmosis. Transbound Emerg Dis 58:1-30

Bilgiç HB, T Karagenç, M Simuunz, B Shiels, A Tait, H Eren, W Weir (2013). Development of a multiplex PCR assay for simultaneous detection of Theileria annulata, Babesia bovis and Anaplasma marginale in cattle. Exp Parasitol 133:222-229

Brito LG, MCDS Oliveira, FGDS Netto, FA Cavalcante, AD Marim, GCRD Souza, JLD Silva, F Benitez, MMDF Moura (2007). Epidemiologia molecular de Anaplasma marginale em bovinos criados nos Estados de Rondônia e Acre. Embr Rondôn Bolet Pesq Desenvolv 49:8-29

Chung C, C Wilson, CB Bandaranayaka-Mudiyanselage, E Kang, DS Adams, LS Kappmeyer, DP Knowles, TF McElwain, JF Evermann, MW Ueti, GA Scoles, SS Lee, TC McGuire (2014). Improved diagnostic performance of a commercial Anaplasma antibody competitive enzyme-linked immunosorbent assay using recombinant major surface protein 5-glutathione S-transferase fusion protein as antigen. $J$ Vet Diagn Invest 26:61-71

Costa SCL, VCSD Magalhães, UVD Oliveira, FS Carvalho, CPD Almeida, RZ Machado, AD Munhoz (2016). Transplacental transmission of bovine tick-borne pathogens: Frequency, co-infections and fatal neonatal anaplasmosis in a region of enzootic stability in the northeast of Brazil. Ticks Tick Borne Dis 7:270-275

Dikmans G (1950). The transmission of anaplasmosis. Amer J Vet Res 11:5-16

Estrada-Peña A, V Naranjo, K Acevedo-Whitehouse, AJ Mangold, KM Kocan, JDL Fuente (2009). Phylogeographic analysis reveals association of tick-borne pathogen, Anaplasma marginale, MSP1a sequences with ecological traits affecting tick vector performance. BMC Biol 7; Article 57

Ewing SA (1981). Transmission of Anaplasmamarginale by arthropods. In: The Natural History of Anaplasma Marginale. Vet Parasitol 167:95107

Farooqi SH, M Ijaz, MI Rashid, H Nabi, S Islam, AI Aqib, K Hussain, A Khan, SNB Rizvi, S Mahmood (2018). Molecular epidemiology of bovine anaplasmosis in Khyber Pakhtunkhwa, Pakistan. Trop Anim Health Prod 50:1591-1598

Grau HEG, NAD Cunha Filho, FG Pappen, NA da R. Farias (2013). Transplacental transmission of Anaplasma marginale in beef cattle chronically infected in southern Brazil. Rev Bras Parasitol Vet 22:189-193

Hawkins JA, JN Love, RJ Hidalgo (1982). Mechanical transmission of anaplasmosis by tabanids (Diptera: Tabanidae). Amer $J$ Vet Res 43:732-734

Henker LC, MP Lorenzett, R Fagundes-Moreira, AG Cabrera Dalto, L Sonne, D Driemeier, JF Soares, SP Pavarini (2020). Bovine abortion, stillbirth and neonatal death associated with Babesia bovis and Anaplasma spp. infections in Southern Brazil. Ticks Tick-borne Dis 11; Article 101443

Karim S, K Budachetri, N Mukherjee, J Williams, A Kausar, MJ Hassan, S Adamson, SE Dowd, D Apanskevich, A Arijo, ZU Sindhu, MA Kakar, RMD Khan, S Ullah, MS Sajid, A Ali, Z Iqbal (2017). A study of ticks and tick-borne livestock pathogens in Pakistan. PLoS Negl Trop Dis 11; Article e0005681

Nazar M, MA Khan, AA Shah, SU Rahman, I Khan, A Ullah, IU Khan, M Shuaib (2018). Occurrence and transplacental transmission of Anaplasma marginale in dairy cattle. Slov Vet Res 55:183-191 
Pohl AE, A Cabezas-Cruz, MFB Ribeiro, JAGD Silveira, C Silaghi, K Pfister, LMF Passos (2013). Detection of genetic diversity of Anaplasma marginale isolates in Minas Gerais, Brazil. Rev Bras Parasitol Vet 22:129-135

Potgieter FT, LV Rensburg (1987). The persistence of colostral Anaplasma antibodies and incidence of in utero transmission of Anaplasma infections in calves under laboratory conditions. Onderstepoort $J$ Vet Res 54:557-560

Pypers AR, DE Holm, JH Williams (2011). Fatal congenital anaplasmosis associated with bovine viral diarrhoea virus (BVDV) infection in a crossbred calf. J S Afr Vet Assoc 82:179-182

Rehman A, FJ Conraths, C Sauter-Louis, J Krücken, AM Nijhof (2019). Epidemiology of tick-borne pathogens in the semi-arid and the arid agro-ecological zones of Punjab province, Pakistan. Transbound Emerg Dis 66:526-536

Ribeiro MF, JD Lima, AM Guimaräes, MA Scatamburlo, NE Martins (1995). Transmissäo congênita da anaplasmose bovina. Arq Bras Med Vet Zootec 47:297-304

Rikihisa Y (1991). The tribe Ehrlichieae and ehrlichial diseases. Clin Microbiol Rev 4:286-308

Sajid MS, RM Siddique, SA Khan, Z Iqbal, MN Khan (2014). Prevalence and risk factors of anaplasmosis in cattle and buffaloe populations of district Khanewal, Punjab, Pakistan. Glob Vet 12:146-153

Salabarria FF, R Pino (1988). Vertical transmission of Anaplasma marginale in cows affected in late pregnancy. Rev Cub Cienc Vet 19:179-182

Santarosa BP, GN Dantas, DOL Ferreira, NS Rocha, RC Gonçalves, RM Amorim, SB Chiacchio (2013). Infecção neurológica por Babesia bovis em bovino neonato: Relato de caso. Vet Zootec 20:9-14

Silva JB, LR Goncalves, ADM Varani, MR André, RZ Machado (2015). Genetic diversity and molecular phylogeny of Anaplasma marginale studied longitudinally under natural transmission conditions in Rio de Janeiro, Brazil. Ticks Tick Borne Dis 6:499-507
Silva JBD, AHD Fonseca (2014). Risk factors for anaplasmosis in dairy cows during the peripartum. Trop Anim Health Prod 46:461-465

Silva JBD, WMS Vinhote, CMC Oliveira, MR Andre, RZ Machado, AHD Fonseca, JD Barbosa (2014). Molecular and serological prevalence of Anaplasma marginale in water buffaloes in northern Brazil. Ticks Tick-borne Dis 5:100-104

Silvestre BT, JAG Silveira, RM Meneses, EJ Facury-Filho, AU Carvalho, MFB Ribeiro (2016). Identification of a vertically transmitted strain from Anaplasma marginale (UFMG3): Molecular and phylogenetic characterization, and evaluation of virulence. Ticks Tick Borne Dis 7:80-84

Spare MR, GA Hanzlicek, KL Wootten, GA Anderson, DU Thomson, MW Sanderson, RR Ganta, KE Reif, RK Raghavan (2020). Bovine anaplasmosis herd prevalence and management practices as risk factors associated with herd disease status. Vet Parasitol 3; Article 100021

Stuen S, W Okstad, AM Sagen (2018). Intrauterine transmission of Anaplasma phagocytophilum in persistently infected lambs. Vet Sci 5; Article 25

Vos AJVD, GD Imes, JS Cullen (1976). Cerebral babesiosis in a new-born calf. Onderstepoort $J$ Vet Res 43:75-78

Wen XB, HT Jiang, YL Zhang, XY Lang, J Liu, HB Ni (2016). Rapid and sensitive diagnosis of cattle anaplasmosis by loop-mediated isothermal amplification (LAMP). Pak Vet J 36:174-178

Walker AR, A Bouattour, JL Camicas, A Estrada-Peña, IG Horak, AA Latif, RG Pegram, PM Preston (2014). Ticks of Domestic Animals in Africa: A Guide to Identification of Species, pp:3-210. Bioscience Reports, Edinburgh, Scotland, UK

Zaugg JL (1985). Bovine anaplasmosis: Transplacental transmission as it relates to stage of gestation. Amer J Vet Res 46:570-572

Zaugg JL, KL Kuttler (1984). Bovine anaplasmosis: In utero transmission and the immunologic significance of ingested colostral antibodies. Amer J Vet Res 45:440-443 